\title{
Correction to: Proposal of a new conceptual gait model for patients with Parkinson's disease based on factor analysis
}

Ilaria Arcolin', Stefano Corna ${ }^{1}$, Marica Giardini ${ }^{*}$ (D), Andrea Giordano ${ }^{1}$, Antonio Nardone ${ }^{1,2}$ and Marco Godi ${ }^{1}$

${ }^{*}$ Correspondence: marica.giardini@icsmaugeri.it

1 Istituti Clinici Scientifci Maugeri Spa SB (IRCCS), Pavia, Italy

Full list of author information is available at the end of the article

\section{Correction to: BioMed Eng OnLine (2019) 18:70 https://doi.org/10.1186/s12938-019-0689-3}

It was highlighted that the original article [1] had an omission in the Abstract. This Correction article shows the omitted sentence: "This article [1] was awarded the SIAMOC Best Methodological Paper 2018".

Author details

${ }^{1}$ Istituti Clinici Scientifci Maugeri Spa SB (IRCCS), Pavia, Italy. ${ }^{2}$ Department of Clinical-Surgical, Diagnostic and Pediatric Sciences, University of Pavia, Pavia, Italy.

The original article can be found online at https://doi.org/10.1186/s12938-019-0689-3.

Published online: 23 July 2019

Reference

1. Arcolin I, Corna S, Giardini M, Giordano A, Nardone A, Godi M. Proposal of a new conceptual gait model for patients with Parkinson's disease based on factor analysis. BioMed Eng OnLine. 2019;18:70. https://doi.org/10.1186/s1293 8-019-0689-3.

\section{Publisher's Note}

Springer Nature remains neutral with regard to jurisdictional claims in published maps and institutional affiliations. 